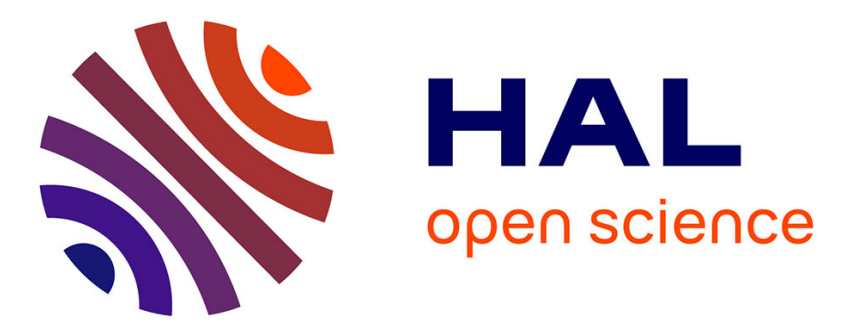

\title{
Transformations of the chemical signature of slag inclusions throughout experimental refining and first shaping of bloomery iron: New methodological developments
}

Alexandre Disser, Sylvain Bauvais, Philippe Dillmann

\section{To cite this version:}

Alexandre Disser, Sylvain Bauvais, Philippe Dillmann. Transformations of the chemical signature of slag inclusions throughout experimental refining and first shaping of bloomery iron: New methodological developments. Journal of Archaeological Science: Reports, 2020, 34, pp.102653. 10.1016/j.jasrep.2020.102653 . hal-03009578

\section{HAL Id: hal-03009578 https://hal.science/hal-03009578}

Submitted on 27 Sep 2021

HAL is a multi-disciplinary open access archive for the deposit and dissemination of scientific research documents, whether they are published or not. The documents may come from teaching and research institutions in France or abroad, or from public or private research centers.
L'archive ouverte pluridisciplinaire HAL, est destinée au dépôt et à la diffusion de documents scientifiques de niveau recherche, publiés ou non, émanant des établissements d'enseignement et de recherche français ou étrangers, des laboratoires publics ou privés. 
Transformations of the chemical signature of slag inclusions throughout experimental refining and first shaping of bloomery iron: new methodological developments ${ }^{1}$

Alexandre Disser ${ }^{1}$, Sylvain Bauvais ${ }^{1-2}$, Philippe Dillmann ${ }^{1-2}$

${ }^{1}$ Laboratoire Métallurgies et Cultures, IRAMAT UMR 5060, CNRS, Université de Technologie de Belfort-Montbéliard

${ }^{2}$ Laboratoire Archéomatériaux et Prévision de l'Altération, NIMBE UMR 3685, CEA, CNRS, Université Paris-Saclay

Corresponding author: disser.alex@gmail.com

Highlights

- A convenient way of sorting non-metallic inclusions in iron artefacts

- Experiments for assessing the chemical impact of smithing fluxes

- A spatial approach of the chemical features of iron artefacts

Abstract

Archaeometallurgical experiments have been conducted on the "Plateforme d'expérimentation des arts du feu" in Melle (Deux-Sèvres, France) in order to get a better understanding of the potential alteration of the chemical signature of non-metallic inclusions in iron artefacts. This alteration may likely be caused by the use of fluxes during the smithing work. Five experimental sequences have been performed, following distinct patterns regarding the use of flux. Cross-sections made from the experimental products have sustained an as exhaustive as possible chemical characterization, resulting in the analysis of several thousands of inclusions per sample. An adapted data treatment procedure, relying on the use of multivariate analyses and geographic information systems, has been set up in order to identify the origin of each inclusion: smelting or smithing.

Keywords: Non-metallic inclusions, multivariate classification, experimental archaeometry, iron artefacts, chemical analyses, bloom smithing

\section{Introduction}

Research carried out in iron archaeometallurgy has increasingly relied on the study of slag inclusions generated during the ore smelting process. Though they have been in the focus of researchers for

\footnotetext{
${ }^{1}$ This paper is part of a Special Issue on the Contributions of Experimental Archaeology to Excavation and Material Studies, guest edited by Frederik W. Rademakers, Georges Verly, Florian Téreygeol and Johannes Auenmüller.
} 
forty years now (Todd and Charles, 1978; Hedges and Salter, 1979), their study has benefitted from continuous analytical developments that now allow an exhaustive acquisition of cross-sections. The petrographic and, above all, chemical characteristics of slag inclusions are induced by the material components of the smelting system, as well as the conduct of the operation (Crew, 2000; Fluzin, 2002; Leroy and Ploquin, 1994; Serneels et al., 2001). These characteristics are thus used to develop a technical approach to the production of ferrous alloys (identifying the technical process, the nature of the materials used, and determining the parameters of the operation, such as the temperature or the air inflow). They are also used at a broader scale to reconstruct the socio-economic systems integrating these production activities, particularly through provenance studies (for a recent review of the literature related to this topic see Charlton, 2015).

However, these questions cannot be addressed through the analysis of any inclusion. Depending on their mineralogy, smelting inclusions may undergo alterations during the post-smelting stages. One of these phenomena is due to a difference in the plasticity of the minerals during the heating and hammering phases of the metal, which leads to the fragmentation of some of them (Mahé-Le-Carlier and Ploquin, 1999; Paynter et al., 2015), thus generating new inclusions for which the original chemical features may be altered. Furthermore, the use of fluxes (sands, clays, salts...) during forging to strip or protect the metal surfaces can lead to the formation of new inclusions that are not linked to the smelting operation. It is therefore essential to ensure that the inclusions considered are characteristic of the smelting system. This implies an accurate identification of the different kinds of inclusions contained in the metal. This identification is all the more simple as the observed population is large. Previous papers have extensively discussed the issue of representativeness at the scale of the observed samples (Charlton et al., 2012; Dillmann and L'Héritier, 2007).

The main purpose of this contribution is to propose some tools aimed at addressing questions commonly raised in iron archaeometallurgy, which are difficult to solve on the basis of archaeological remains, as the operating parameters are largely unknown to us. To this end, a campaign of archaeological experiments has been performed on the "Plateforme d'expérimentation des arts du feu" in Melle (Deux-Sèvres, France). It involved two professional blacksmiths, used to working in operating conditions prior to the Industrial Revolution (ventilation through bellows, charcoal as fuel, etc.). This experimentation was the opportunity to use forging fluxes of which the nature and the chemical signature were known.

Experimental archaeology for iron metallurgy has largely focused on the reconstruction of smelting systems. Forging stages, understood here as all the operations designed to obtain finished products from raw metallic masses, has only been the subject of a small number of experimental works, even though a great many questions have been raised by the multiplication of archaeometric studies on iron artefacts. In particular, the conservation of the chemical signature characteristic of the smelting system is a crucial issue. These studies have highlighted three main factors on which this conservation depends throughout the post-smelting steps: 1) the elimination of smelting-related inclusions; 2) physicochemical modifications of smelting-related inclusions; 3 ) the formation of new inclusions, mainly linked to the use of addings (Blakelock et al., 2009; Charlton et al., 2012; Dillmann and L'Héritier, 2007).

In order to specify the influence of these factors on the preservation of the initial chemical signature, it is therefore essential to carry out the most exhaustive possible chemical characterisation of 
metallic samples taken at different stages throughout the forging process. Thus this work is based on recent developments of analytical devices commonly used in iron archaeometallurgy to develop a workflow that allows an exhaustive analysis of the chemical signature of slag inclusions trapped in ferrous products. These developments make it possible to chemically characterize almost all the inclusions visible on a cross-section, thus providing exhaustive chemical information at the sample scale. The large quantities of data generated (about fifteen variables for several thousand individuals) required the implementation of an adapted data processing protocol, relying on a customized data processing with $\mathrm{R}$, and the use of GIS to facilitate the spatial display of various queries.

\section{Experimental protocol}

The raw metal used has been obtained experimentally by $\mathrm{M}$. Leroy and P. Merluzzo by smelting an Aalenian oolitic ore (the "Minette Lorraine") on the "Musée de l'histoire du fer" experimental platform (Nancy-Jarville, France). This ore has been chosen because of its very particular chemical composition (high relative contents of $\mathrm{Mg}, \mathrm{Al}, \mathrm{P}$ and $\mathrm{Ca}$ ). This peculiar chemical signature was expected to facilitate the identification of smelting-related inclusions within the experimental products. A series of five operating sequences has then been undertaken on the "Plateforme d'expérimentation des arts du feu" in Melle. It has been carried out by a professional blacksmith, who is used to forging metal obtained from the "Minette" ore, and to work with charcoal as fuel.

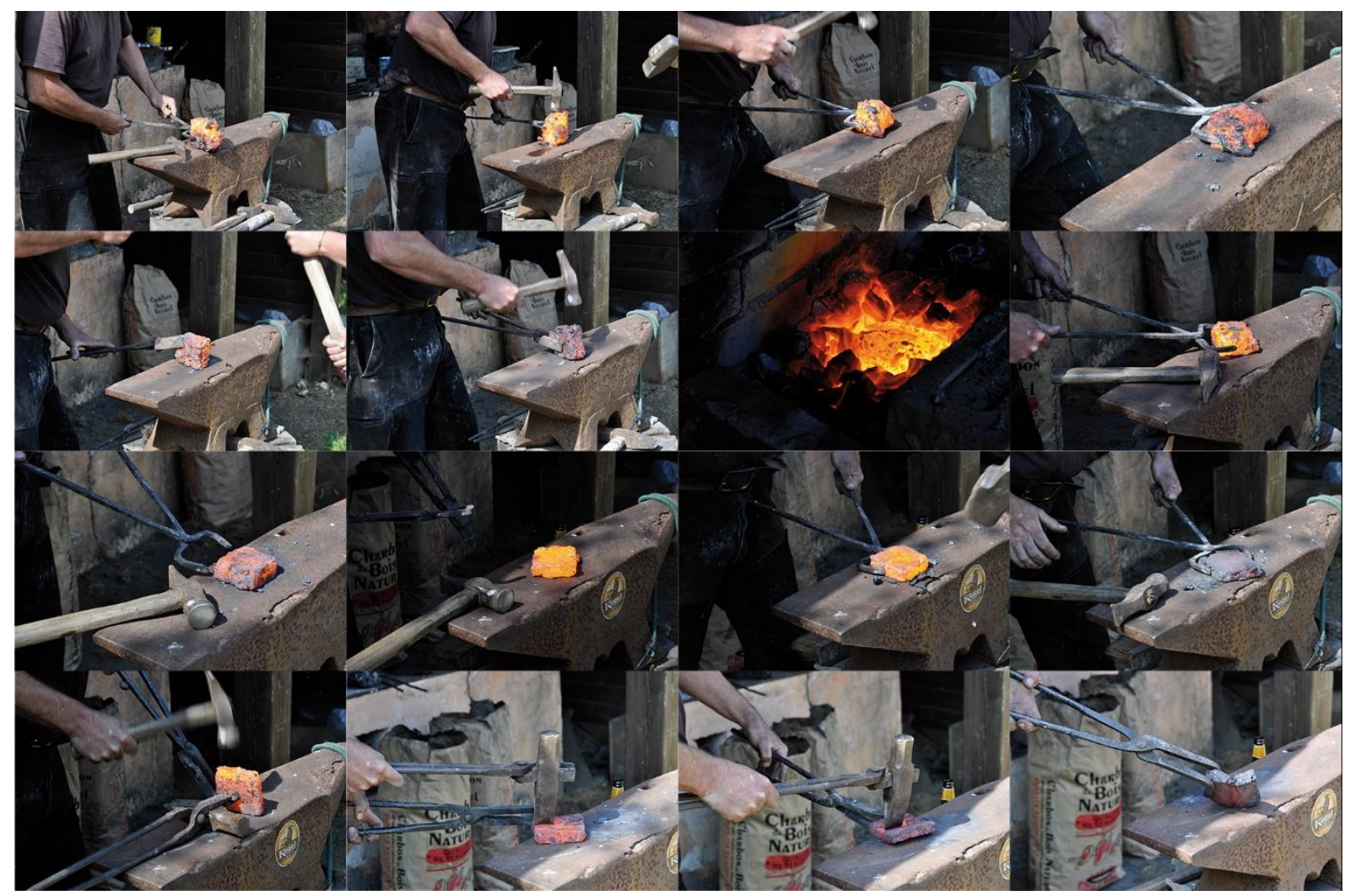

Fig. 1: Sequences 1_1_1 and 1_2_1 of bloom refining and shaping of the two bars (hot cutting of the refining bloom into two bars.). Reading from left to right and top to bottom.

Three crude iron blooms have been refined and shaped to bars; the two largest specimens were split into two smaller ones (1-1, 1-2, 3-1 and 3-2). All the operating sequences followed the same protocol: compacting and cleaning of the bloom; first elongation of the refining mass for bar shaping 
(fig. 1); bending/welding of the bar; second elongation of the bar; second bending/welding; third elongation of the bar (fig. 2). The nomenclature of the samples is as follows XPEPU15_A_B_C, where $A$ is the number of the original bloom, $B$ is the number of the sequence, and $C$ is the stage at which the metal has been sampled (1: at the end of the refining stage, 2: after the first bending/welding operation, 2: after the second bending/welding operation). Experimental sequences are summarized in Table 1. 


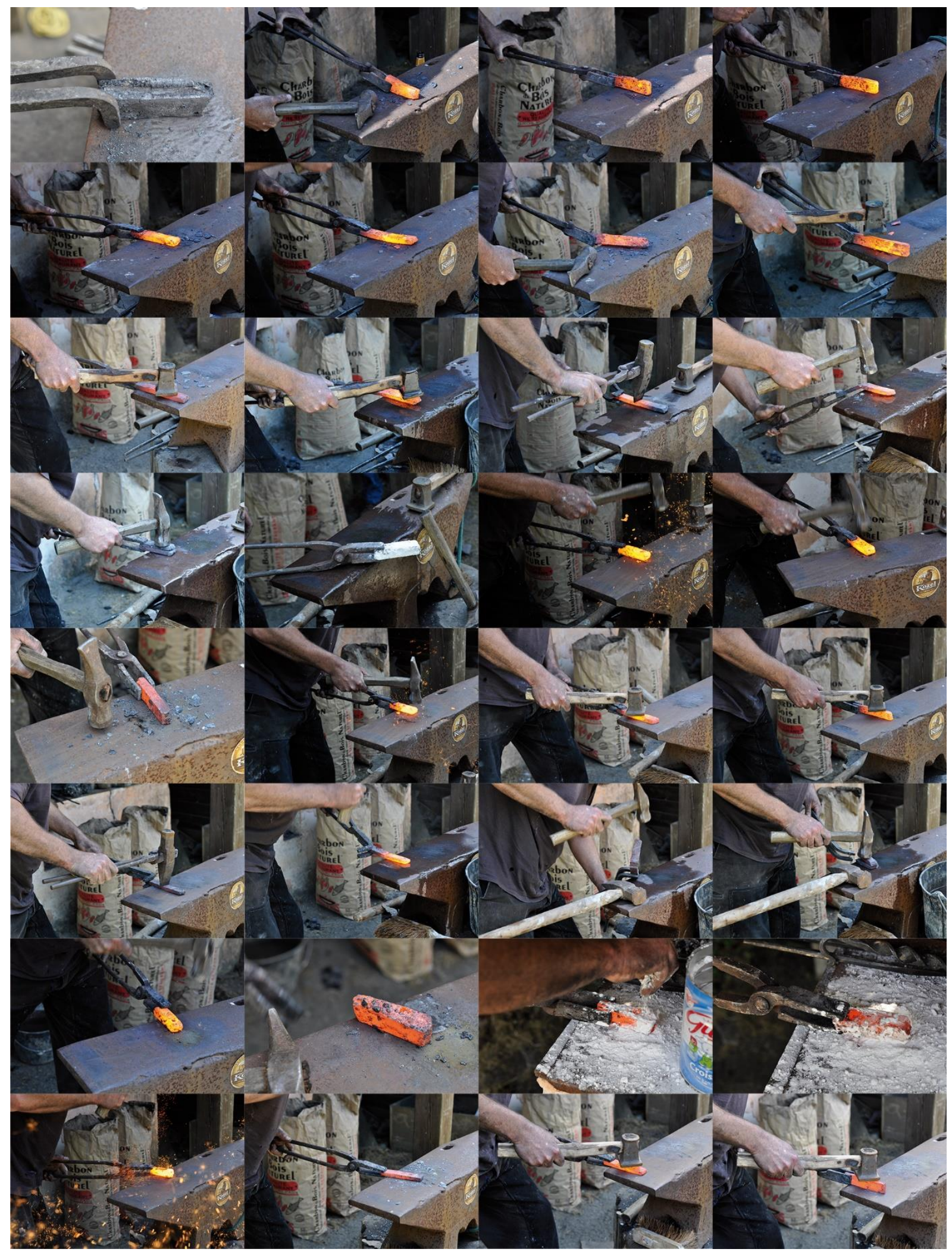

Fig. 2: Sequences 1_1_2 and 1_1_3 of elongating the bar, first folding and welding, elongating the bar and second folding and welding. Reading from left to right and top to bottom.

\begin{tabular}{|c|c|c|c|c|c|}
\hline Bloom & \multicolumn{2}{|c|}{ Bloom 1 } & Bloom 2 & \multicolumn{2}{c|}{ Bloom 3 } \\
\hline Sequence & $1 \_1$ & $1 \_2$ & 2 & $3 \_1$ & 3_2 \\
\hline
\end{tabular}




\begin{tabular}{|c|c|c|c|c|c|} 
Step 1 (bloom refining) & Glass & Glass & Glass & None & None \\
& $\left(1 \_1 \_1\right)$ & $\left(1 \_2 \_1\right)$ & $\left(2 \_1 \_1\right)$ & (3_1_1) & (3_2_1) \\
\hline $\begin{array}{c}\text { Step 2 (first folding } \\
\text { and welding) }\end{array}$ & Glass & Castel Minier slag & None & None & Glass \\
Step 3 (second folding & Glass & Castel Minier slag & None & None & Glass \\
and welding) & $\left(1 \_1 \_3\right)$ & $\left(1 \_2 \_3\right)$ & $($ 2_1_3) & (3_1_3) & (3_2_3) \\
\hline
\end{tabular}

Table 1: Details about the experimental sequences

In order to assess the quantities of forging inclusions introduced into the mass of metal during the operation, we divided each sequence into two phases of flux use, the first corresponding to the cleaning and compacting of the mass of raw metal, and the second corresponding to the shaping of the metal (stretching of the bar and bends/welds). During the refining stage, approximately a handful of flux has been put on the metal. While the use of fluxes during this early stage has not been documented archaeologically, we wanted to assess to what extent the porosity of the crude metal could have favoured the generation of new inclusions through pollution from the refining hearth. During the shaping of the bars and the bending/welding operations, flux has been used in such a way as to fully cover the surface of the metal. Two types of fluxes likely to have been used in a forge workshop context were used. The first is a slag collected at the Castel-Minier ironmaking workshop (Ariège, France). This slag contains fair amounts of Manganese that is intended to be used as a tracer element. The second one is a sodic glass that was obtained by crushing scraps of glass from a craft glass factory (Silycibine workshop in Arcueil, France). Both materials have been ground to a grade of about $100 \mu \mathrm{m}$. These two materials have previously been chemically characterized by SEM-EDS. Their chemical composition is shown in fig. 3. The "Minette slag" data are given as reference for the smelting-related inclusions. The amounts given are the mean values of 11 slag samples produced by the experimental smelting of "Minette" ore. The amounts for "Castel-Minier" slag are the mean values of 17 measures made on the powder. The data for the sodic glass are the mean values of 21 measures made on the powder.

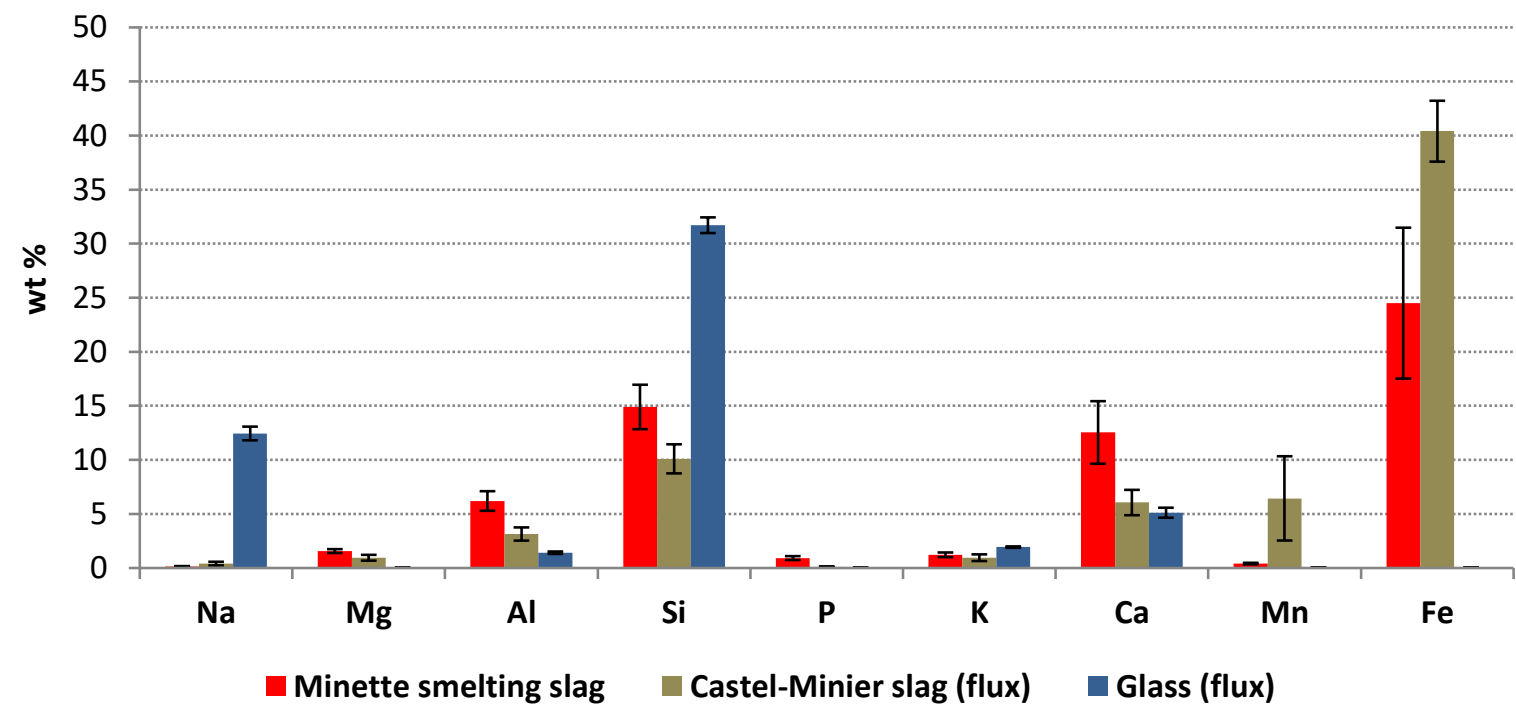

Fig. 3: Main chemical features of the experimental smelting slag (Minette) and the two fluxes (CastelMinier slag and glass) 
Three samples were taken throughout each sequence: a sample of the raw bloom at the end of the cleaning phase; a sample of the bar before the first bending/welding; a sample of the bar after the second bending/welding. By this way, it is possible to evaluate the quantity of slag inclusions that are expelled from the metal during the process, as well as the quantity of forging inclusions that are generated.

\section{Analytical approach}

\subsection{Sample preparation and micrographic exams}

The samples were embedded in epoxy resin and polished (from grade 80 to a $1 \mu \mathrm{m}$ diamond suspension). Each cross-section was then subjected to a metallographic examination after acid etching (Nital with 3 vol\% of $\mathrm{HNO}_{3}$ in ethanol). This first examination revealed the distribution of carburized structures, as well as features linked to the welds. A second examination of the polished section was carried out after repolishing, in order to examine the inclusions (distribution, quantity, petrography). A mosaic of pictures was acquired at each of these stages, providing comprehensive digital images of each cross-section.

\subsection{Chemical characterization of the inclusions}

The cross-sections were then subjected to elemental analysis by energy dispersive $\mathrm{X}$-ray spectrometry coupled with scanning electron microscopy (SEM-FEG JEOL 7001-F equipped with a silicon-drift detector). The accelerating voltage was set at $15 \mathrm{kV}$ and the probe current at about $8 \mathrm{nA}$. This setup allows reliable quantification for elements whose amounts are superior to a threshold comprised between 0.3 and $0.5 \mathrm{wt} \%$, depending on the chemical element considered. Through this analytical device, coupling imaging and quantification of major chemical elements, several thousands to tens of thousands of entities can be characterized based on brightness values (levels of grey) obtained from backscattered-electron imaging. Metal has high values (white) while inclusions, porosities and corrosion products have low values (grey to black). Each aggregate of dark pixels (inclusion, porosity or corrosion) is analyzed and defined as an entity. Using the automated microscope motion system, each entity is spatially referenced. All image and chemical data have been primarily processed using Aztec software (Oxford Company). An automated filter has been applied on each spectrum to remove the background contribution. Quantification of chemical elements has been processed using XPP matrix correction routine (with a Phi-Rho-Z function). The following elements have been systematically quantified: $\mathrm{O}, \mathrm{Na}, \mathrm{Mg}, \mathrm{Al}, \mathrm{Si}, \mathrm{P}, \mathrm{S}, \mathrm{Cl}, \mathrm{K}, \mathrm{Ca}, \mathrm{Ti}, \mathrm{V}, \mathrm{Cr}, \mathrm{Mn}$, Fe. The results have been normalized to $100 \%$. A spreadsheet comprising spatial, morphological and chemical information for each particle is generated at the end of this process.

\subsection{Data processing procedure}

The large volumes of data that are acquired have necessitated the establishment of an adapted data processing protocol, which will be described in this section. The aim is to obtain a data set that can be analyzed by means of multivariate statistics. To this end, the adopted data processing allows the removal of outliers (entities that are not inclusions or for which the analysis conditions are not good enough) and the processing of missing data (mainly related to measure below the detection limits). This procedure is transcribed in the form of a program in $R$, whose code is provided as Supplementary Materials. Each step described below is tagged within the script. 


\subsubsection{Dealing with detection limits}

The amounts of some elements of interest (particularly $\mathrm{Na}, \mathrm{Mg}$ and $\mathrm{Mn}$ ) are below detection limits for a significant number of inclusions. Even low concentrations of these elements provide useful information for defining chemical groups of inclusions in samples. We have therefore chosen not to exclude these inclusions, as this would mean losing significant amounts of information. We therefore opted for imputation of low concentrations. We are in the case of "censored data", i.e., the low concentrations are in a range bounded by a zero concentration and the limit of detection (LoD) threshold. Several procedures are available, and have been the subject of numerous publications (a review is proposed by (Helsel, 2010)). We discarded the substitution of missing data with a specific concentration (e.g. half the LoD), as this causes biases in multivariate analysis (e.g. generation of linear clouds at the factorial level). We therefore opted for random generation of concentrations in the range between zero and the limit of detection. A classical approach consists in generating these contents according to a normal distribution. We rejected this strategy because it assumes that the majority of the levels would be equal to half the detection limit (modal value of a normal distribution). Therefore, we opted for a uniform distribution generation, which seems to best fit the present situation (equal probability of the grade in question being between null value and the detection limit) (Little and Rubin, 2019, pp. 67-69).

\subsubsection{Sorting SEM-EDXS particles out}

An automated procedure is then applied to eliminate aberrant entities and keep only the inclusions. The first selection criterion is the accuracy of measurement for the most abundant inclusion compounds. Accuracy is expressed as the ratio between a measured content and its associated measurement error. The ratio used is 0.1: the measured value must therefore be at least 10 times greater than the measurement error. This ratio is calculated successively for $\mathrm{O}, \mathrm{Fe}, \mathrm{Si}, \mathrm{Al}$ and $\mathrm{Ca}$. If only one of these conditions is not met, the inclusion is eliminated from the dataset.

\subsubsection{Taking into account different kinds of ferrous compounds}

The conditions of particle analysis (image contrast, grey level thresholds, sample surface geometry, particle shape) may cause the metal matrix to contribute to a greater or lesser extent to the chemical characterization. In order to avoid this bias, a filter based on the stoichiometric balance of inclusions was used. Iron is assumed to be mainly present under valence II (forming wüstite FeO or fayalite $\mathrm{Fe}_{2} \mathrm{SiO}_{4}$ ). Each elemental concentration is converted into oxide. The sum of the concentrations expressed as oxides is therefore close to $100 \%$, depending on whether the iron measured is of valence II. In the case of an important assay of the matrix (or metallic iron), this sum differs strongly from the theoretical sum of $100 \%$. Different thresholds have been tested in order to avoid discarding too much valid particles and keeping biased ones. For this study, a sum of oxides lower than $80 \%$ or higher than $120 \%$ has proven satisfactory, albeit narrower intervals could be used for a stricter selection.

\subsection{Defining chemical groups of inclusions}

The multivariate approach to identifying chemical groups of inclusions proposed here builds on previous studies that have used major elements for reconstructing technical systems (Charlton et al., 2010) or identifying the origin of the metal (Disser et al., 2016). 
Raw elemental contents cannot be used, as they are highly dependent on the proportion of iron oxides within the inclusions, which is highly variable. Moreover, some elements (such as Si or $\mathrm{Ca}$ ) are present in contents up to ten times higher than those of other elements ( $\mathrm{Na}, \mathrm{Mg}$ or $\mathrm{Mn}$ ). To prevent the analyses to be over influenced by these factors, a transformation has to be applied to the data. The various means of data transformation applied to archaeometallurgical problems have been widely discussed in several articles (Aitchison, 1986; Baxter and Freestone, 2006; Charlton et al., 2012; Leroy et al., 2012). In the present study, the chemical composition is expressed in centred and reduced log-ratios. The transformed variables, referred to as $\mathrm{Xij}$, were calculated using the logarithms of $\mathrm{Si}, \mathrm{Al}$ and $\mathrm{Ca}$ contents as denominators of the ratio, as they are the most abundant elements in the inclusions (apart from $\mathrm{O}$ and $\mathrm{Fe}$ ), and hence the most accurately measured elements (Disser et al., 2016). A multivariate Ascending Hierarchical Clustering treatment (hclust function from stats package) is applied to this transformed data (xij_Na, xij_Mg, xij_Al, xij_Si, xij_K, xij_Ca, xij_Mn) to define chemical groups of inclusions. The "ward" algorithm has been used to perform the clustering. Factorial analyses (Principal Component Analysis on transformed data) and matrices of biplots (plotting the elemental amounts for each couple of chemical elements) are also generated, in order to assess the relevance of the clustering.

This data processing is carried out using an R program that we have set up, the code for which is provided as Supplementary Material. The program was run in the RStudio user interface. Several graphs involved in the interpretation of the data (factorial planes, dendrograms, matrices of biplots) are generated by the script and can be recorded through the interface. The processing also provides a dataset containing all selected inclusions (comprising classification results, relative coordinates, dimensions of the inclusions and raw and transformed elemental contents).

\subsection{Spatial data treatment}

This dataset is integrated into a Geographic Information System managed by the QGIS software (version 3.10). The micrographic mosaic is incorporated into this system according to a custom georeferencing system, which makes it possible to examine the organization of inclusions according to their chemical characteristics. For this, we use the software's default georeferencing plugin (https://docs.qgis.org/3.10/en/docs/user manual/plugins/core plugins/plugins georeferencer.html) . The mosaic is implemented by defining three to four control points. To do so, remarkable inclusions are selected within the point cloud. The transformation performed is a "thin plate spline" and the resampling method is the "nearest neighbour". The superimposition of the inclusion point clouds and the micrographic mosaic of the samples allows the groups of inclusions to be compared with the remarkable characteristics of the metal matrix, in particular the weld lines. It then becomes possible, from queries involving different kinds of information (chemical, dimensional, spatial and petrographic), to interpret each group of inclusions: forging inclusions, hercynite inclusions and smelting-related inclusions. This identification, the final stage of the analytical approach, is essential to describe the evolution of the chemical signatures of the inclusions throughout the forging process.

\section{Results and discussions}

\subsection{Clustering performance}

Before examining the distribution and relative amounts of the distinct inclusions classes within the samples, it was necessary to ensure that the implemented data processing procedure, from the 
sorting of raw data to the definition of chemical classes of inclusions by Ascending Hierarchical Clustering, made it possible to obtain a relevant classification. The criterion used for this is the distribution of the transformed variables (the Xijs) according to the class assigned at the end of the processing. A misclassification can be highlighted by the multimodal nature of the Xij distribution for a given class. We tested the unimodal character of the Xij distributions of $\mathrm{Na}, \mathrm{Mg}, \mathrm{Al}, \mathrm{Si}, \mathrm{K}, \mathrm{Ca}$ and $\mathrm{Mn}$ for each inclusion class resulting from the clustering. The Dip test for unimodality computed by J.A. Hartigan was used to verify this character (Hartigan and Hartigan, 1985). The detailed results of these tests are given as Supplementary Materials. The test was performed on 945 Xij series ( 7 Xij per group, 137 groups for 15 samples). The distribution was unimodal for 945 series, i.e. $98.54 \%$ of the cases. The partitioning procedure adopted was therefore effective in highlighting chemically homogeneous classes of inclusions.

The identification of the classes of inclusions will be used to describe the distribution and the evolution of the proportion of forging and smelting inclusions. The importance of the fragmentation (Dillmann and L'Héritier, 2007; Mahé-Le-Carlier and Ploquin, 1999) previously highlighted in the case of the "Minette" can also be accurately assessed. Finally, the classes will be used to discuss the criteria for recognizing and interpreting forge inclusions on archaeological samples.

\subsection{Interpreting inclusion classes}

In order to be able to interpret each class of inclusions, their chemical features (expressed as average contents of each element of interest) were first compared with those of the reference materials: ground glass and Castel-Minier slag, and experimental smelting slag from the "Minette". The sample XPEPU15_1_1_2, obtained after using fluxes during the refining stage, the shaping of the bar and the first bending/welding, will be used as an example. 


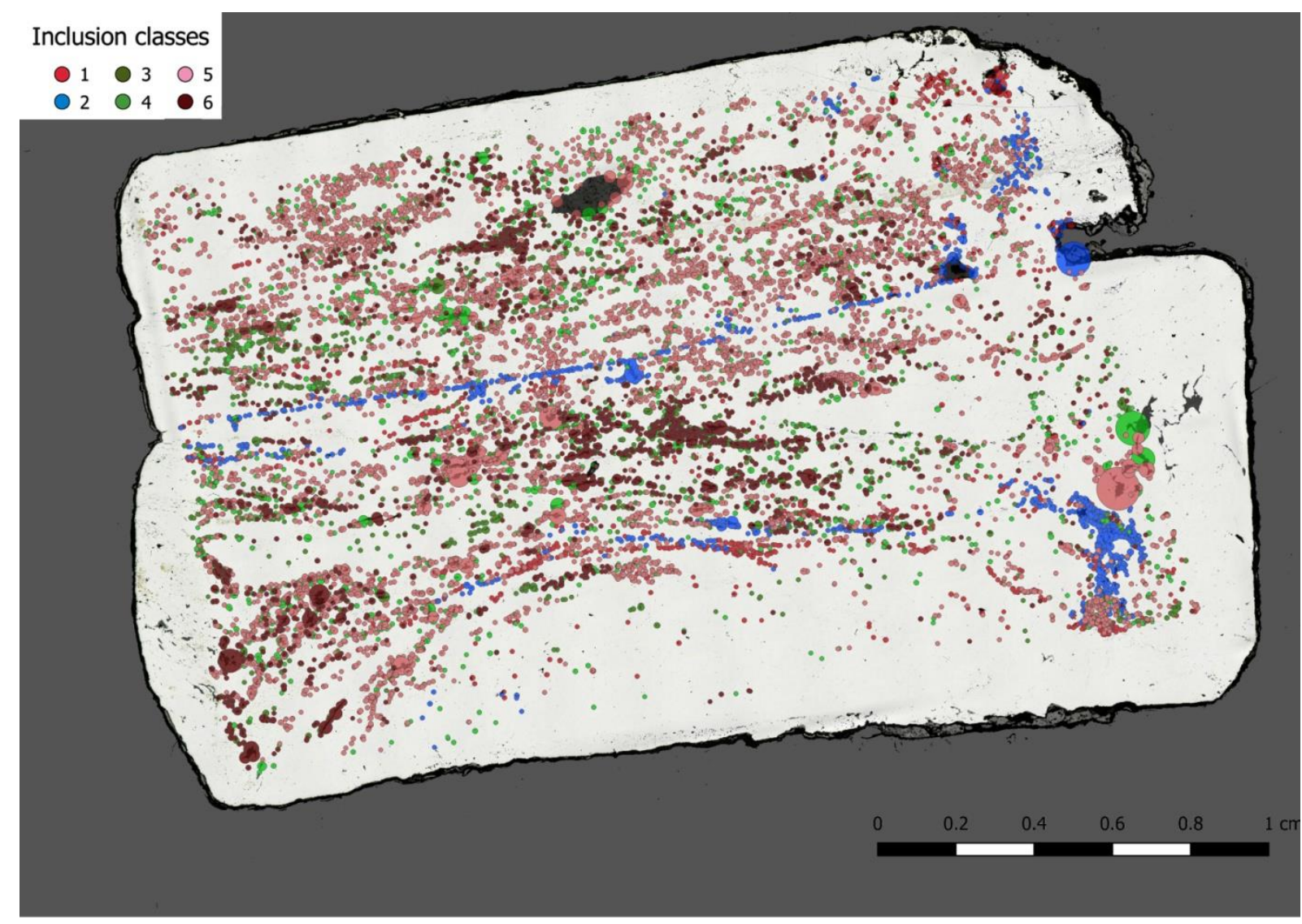

Fig. 4: Cross-section of sample 1_1_2 displaying the inclusion classes obtained through the data treatment procedure. The size of the marker is proportional to the surface of the analyzed particles.

The sampling was carried out after the first bending/welding of the bar obtained from the bloom. Since forging inclusions are generated by the reaction of the fluxes with iron oxides that form on the surface of the metal, the level of iron oxides is significantly higher than in the materials used as flux. In order to compare the absolute contents of the chemical elements, the contents have been normalized to iron content (method described in more detail in Disser et al. 2014). Group 2 shows a high Na content and low Al and Ca contents. These chemical features are similar to those of the glass used as a forging flux in sequence 1_1, and lead to the interpretation that these inclusions are forging-related inclusions. The distribution of inclusions in the metal confirms this hypothesis, with group 2 being clearly located on the weld line (Fig. 4). 


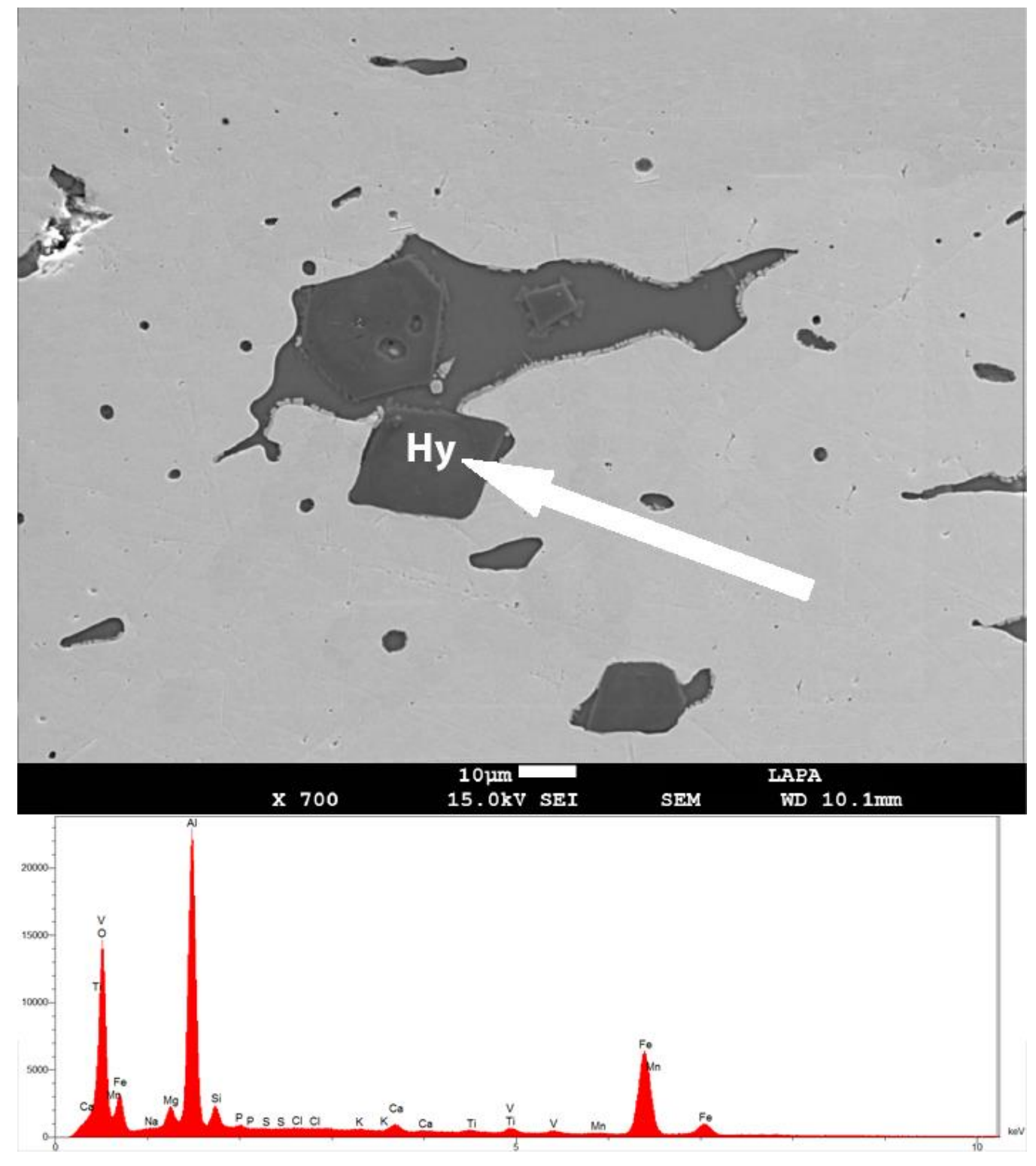

Fig. 5: Top: Secondary electron image showing an inclusion with hercynite crystals; bottom: EDS spectrum acquired on the highlighted crystal

Group 3 shows chemical features that are distinct from those of glass and smelting slag, and is characterized by much higher Al contents. Examination of these inclusions under metallographic microscopy shows that they consist of angular crystals of spinel identified as hercynite (Fig. 5). These crystals are commonly present in the slag resulting from the smelting of "Minette" (Leroy et al., 2015). Some of these crystals appear to be "expelled" from the smelting inclusions due to their plastic deformation while the metal is hammered. These crystals generate inclusions that will be labeled as "hercynite" inclusions.

The chemical features of groups 4,5 and 6 are very consistent with those of the experimental "Minette" smelting slag (Fig. 6). There is little doubt that these inclusions have been generated by 
the smelting operation. Therefore, the inclusions from these three groups carry the smelting system's original chemical signature that can be used to determine the smelting parameters or to identify the origin of the metal.

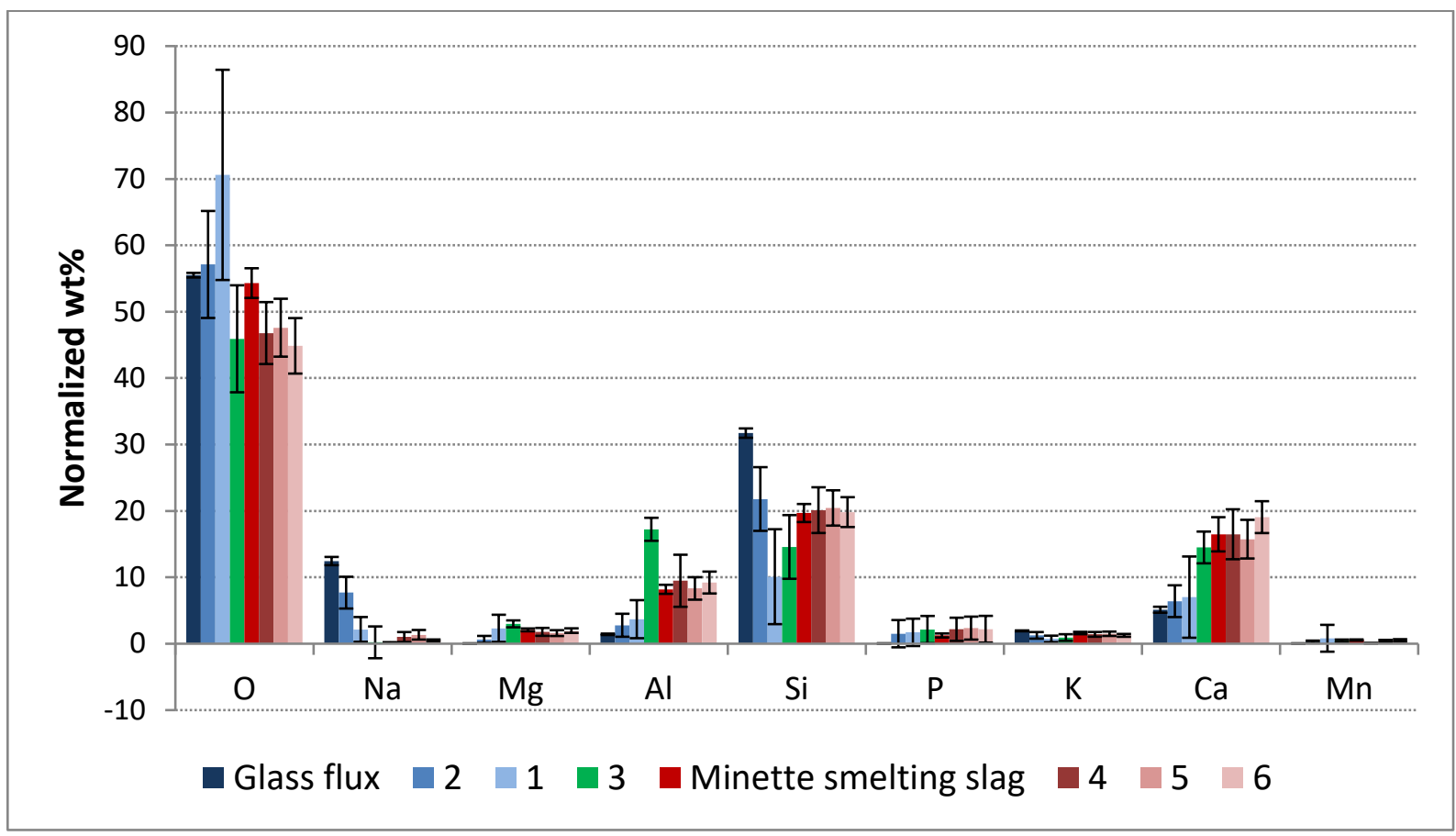

Fig. 6: Main chemical features (mean values) of the reference materials and of the six inclusion groups defined through the data treatment procedure

Inclusions forming group 1 stand out from the other groups, and do not appear related to either the forging flux or the smelting slag. These features are correlated with a very high amount of oxygen. This suggests that these inclusions contain high amounts of iron oxides, and may probably be generated partly by the oxidization of the surface of the metal while heating it. They would therefore be related to the forging process.

The approach presented through this section has been applied to each of the 15 samples taken during the forging experiments. The interpretation of the groups of inclusions will be used to support the results and discussions developed below.

\subsection{Quantitative assessment of the proportions of distinct inclusion types}

As said in the introduction, the formation of inclusions related to forging operations can complicate the determination of the characteristic chemical signature of the smelting system, thus hindering the identification of the source of the metal. This issue has been raised frequently, and has already been the subject of previous studies aimed at assessing the impact of forging operations on the chemical signature of ferrous alloys (Dillmann and L'Héritier, 2007). Performing extensive analyses of crosssections obtained specifically by experimental means offers the opportunity to evaluate the quantities of inclusions formed during the forging process. After interpretation of the groups of inclusions, the proportions of forging and smelting inclusions (as well as the "hercynite" ones) were calculated (Fig. 7). These proportions are expressed by the surface occupied by each interpreted type of inclusion on the polished surfaces of the samples taken at the end of each forging sequence. The 
measurements show that smelting inclusions are dominant in the final sample of all sequences, regardless how frequently flux addings have been used. The lowest proportion remains slightly above $50 \%$ (sequence 1_1).

These results plead for a strong conservation of the chemical signature of the smelting system in ferrous products. However, it should be kept in mind that these sequences were not intended to obtain a fine-worked metal. It can be compared to the quality of products such as hardware elements or architectural implements. Experiments aimed at obtaining finely worked products, such as blades, should be carried out to pursue these thoughts. In any case, the proportions observed (from 50 to 90 percent) for this study are large enough to suggest that even complex and fine products still contain a significant amount of smelting slag inclusions.

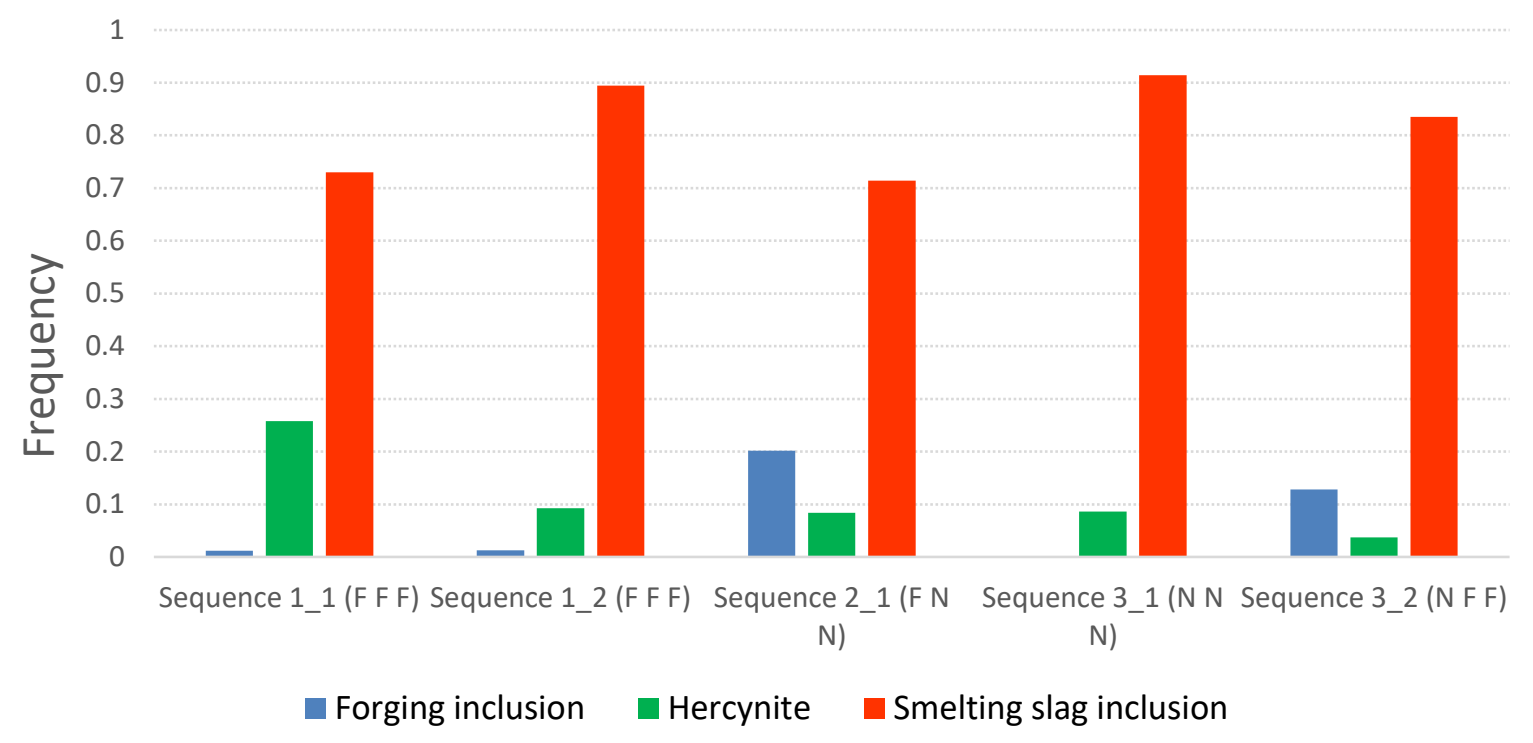

Fig. 7: Frequency of the three types of inclusion in the final product of each experimental sequence

\subsection{Distribution of the types of inclusions within the metal}

Integrating spatial information to the protocol provides an opportunity to examine the distribution of different types of inclusions within the metal. It is of particular importance as it can develop an accurate analysis of how new inclusions are formed during post-reduction operations. A central issue in inclusion studies is to determine whether forging inclusions are exclusively related to features linked to forging (in this case, folds/welds) or are more scattered within the metal.

Although the use of fluxes during the refining phases is not archaeologically evidenced, we used this practice for sequences $1 \_1$ and $1 \_2$ to simulate a case where the formation of post-smelting inclusions would be maximal in a porous material. Samples 1_1_3, 1_2_3 (use of fluxes during refining stage) and 3_2_3 (no fluxes during refining stage) were compared (Fig. 8 to 10). In all three cases, the inclusions identified as related to forging did not appear randomly distributed within the metal. They constitute coherent sets, which develop parallel to the hammering planes. Most of these sets form lines that correspond to the folding/welding surfaces. The comparison of these three experimental products shows that the incorporation of fluxes during the cleaning phase $\left(1 \_1 \_3\right.$ and 
1_2_3) is negligible. In all three cases, the forging inclusions identified appear clearly associated with the use of flux during the two folding/welding stages, during the elaboration of the iron bars. The number of experimental samples is too small to be able to generalize, but these initial results suggest that the inclusions formed by forging operations are much localized within the metal, as they are overwhelmingly associated with the weld lines.

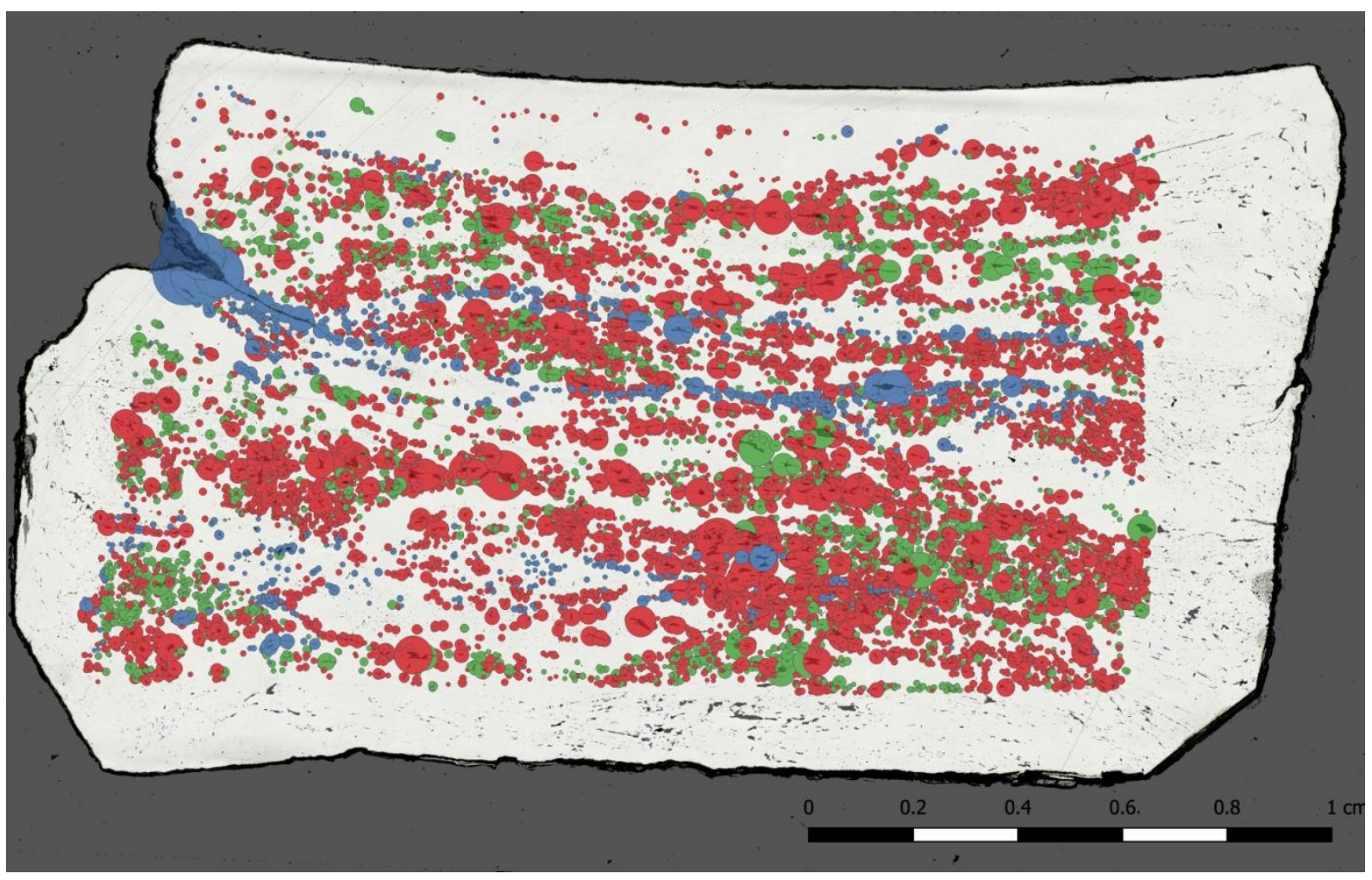

Fig. 8: Distribution of the three inclusion types on the cross section of sample 1_1_3

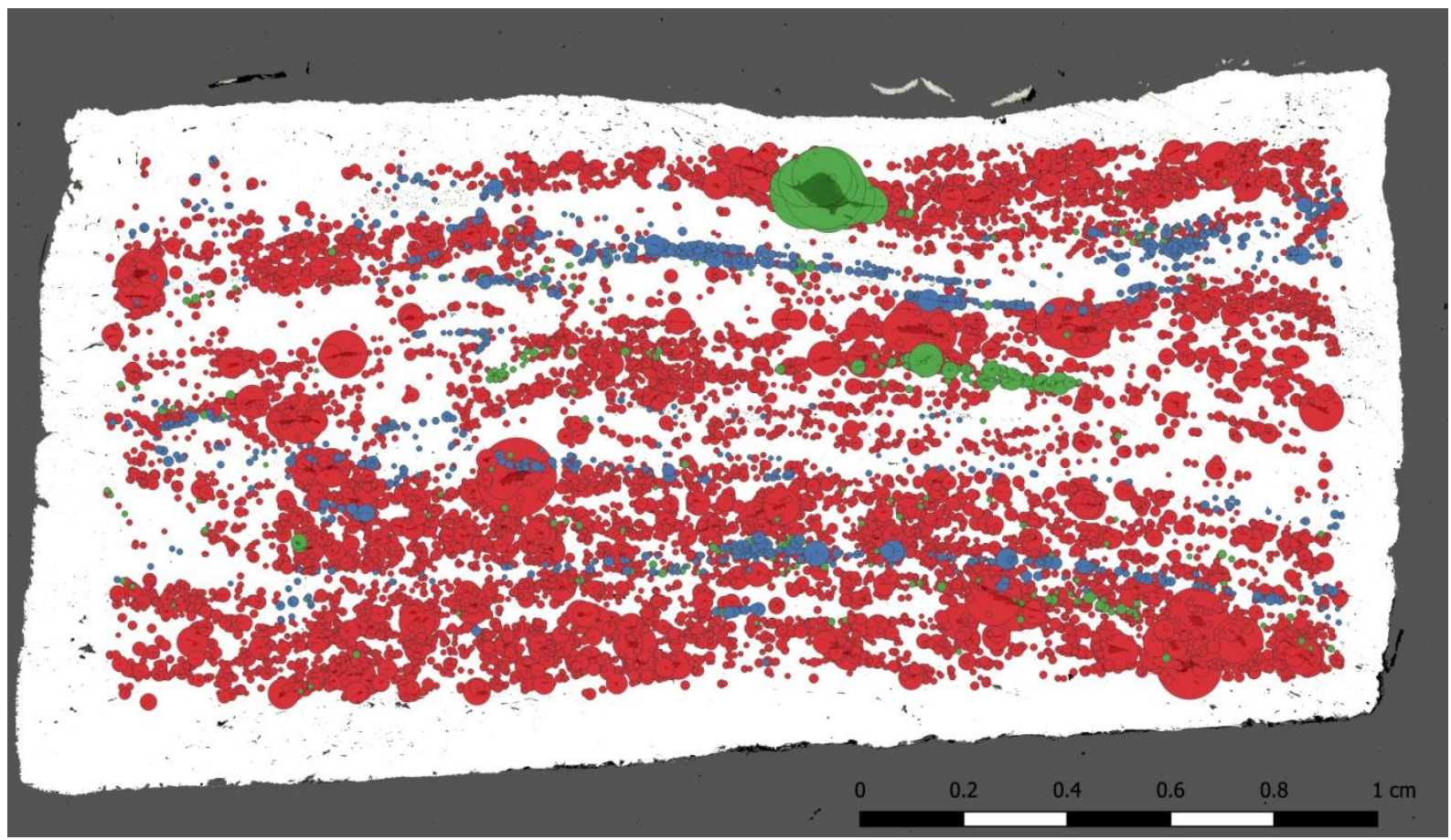

Fig. 9: Distribution of the three inclusion types on the cross section of sample 1_2_3 


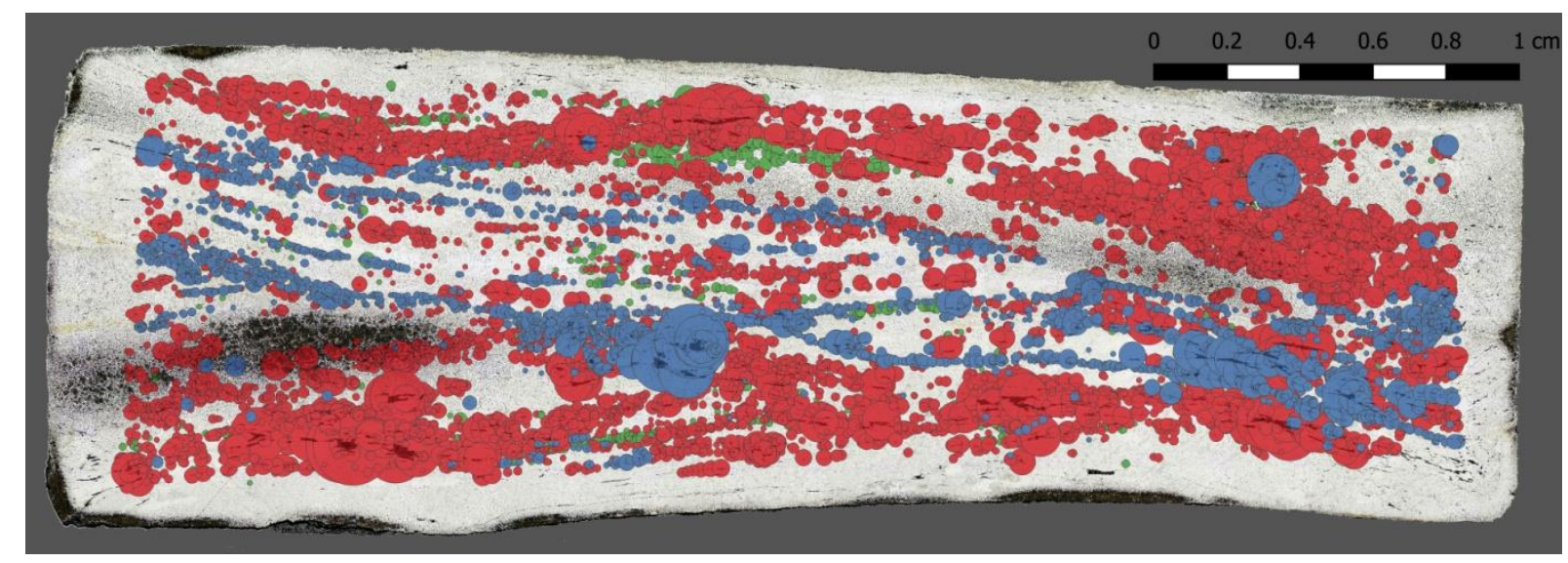

Fig. 10: Distribution of the three inclusion types on the cross section of sample 3_2_3

\subsection{The impact of flux use on metal losses throughout the process}

Not only does this experiment provide us with crucial data on the behaviour of non-metallic inclusions in the metal during the bloom refining and forming phases, it also provides us with important information on the conduct of the processes and the behaviour of the elements as a whole. During its refining and post-smelting shaping, the metal is successively heated in an oxidizing atmosphere and a layer of iron oxide forms on the periphery of the mass. Indeed, with each pass through the fire, part of the metal is lost in the form of oxide. Through their use for removing the oxide scales from the metal surface, fluxes may contribute to prevent excessive oxidation and reduce metal loss. The experiments carried out so far efshow that between the bloom and the bar prepared to be transformed into an object, between 50 and $80 \%$ of metal is lost depending on the initial compaction of the bloom and the technical quality of the blacksmith (Crew, 1991; Crew and Crew, 1994; Dillmann et al., 1997; Leblanc, 2002; Leroy et al., 2000) (Table 2). Within the framework of this experiment, it is possible for us to provide new data on these losses, but above all to compare the importance of these losses according to the use of fluxes, the moment of their use and their type.

\begin{tabular}{|c|c|c|c|}
\cline { 2 - 4 } \multicolumn{1}{c|}{} & \multicolumn{3}{c|}{$\%$ of losses } \\
\cline { 2 - 4 } \multicolumn{1}{c|}{} & min. & max. & av. \\
\hline Bloom refining & 39 & 74 & 52 \\
\hline 2nd refining & 19 & 44 & 28 \\
\hline Bar elaboration & 4 & 45 & 19 \\
\hline Bloom and 2nd refining & 45 & 80 & 63 \\
\hline 2nd refining and bar elaboration & 41 & 64 & 52 \\
\hline Complete refining & 52 & 83 & 73 \\
\hline Object elaboration & 4 & 27 & 13 \\
\hline
\end{tabular}

Table 2: Summary of metal loss proportions by work phase based on Crew, 1991; Crew and Crew, 1994; Dillmann et al. 1997; Leblanc, 2002; and Leroy et al. 2000. 
Thus, during the first stage of bloom refining, the losses of 50 to $56 \%$ achieved during our experiments are quite comparable to the average losses recorded in the other reconstitution works (Table 3). However, it is notable that there is no significant loss difference whether using fluxes or not. This amount of loss seems more correlated with the size and weight of the initial blooms. For the first stage of elongation and folding, the losses, between 20 and $28 \%$, are also very close to the average losses during the first stages of bar shaping. At this stage, a slight difference seems to appear in terms of loss depending on the use of flux or not, and on the use of glass or slag. Bloom 1 shows a loss rate of $20 \%$ using glass (sample 1_1_2) and $28 \%$ with the use of Castel-Minier slag (sample 1_2_2). Finally, the second stage of shaping and kneading shows rates ranging from 16 to $27 \%$, which are perfectly in line with the average of previous experiments. However, using flux or not had a significant impact on the loss of metal during the last steps of the process. The rates are of 16 and $18 \%$ for the two sequences during which glass was used (respectively $1 \_1$ and 3_2). The figures are of 24,24 and $27 \%$ for the three sequences (1_2, 2 and 3_1) during which no flux has been used. The use of slag does not appear to have a significant protective role as it resulted in the same loss rates as when using no flux.

The use of fluxes appears to get more and more effective as the work and the cleaning of the metal progress. It is also remarkable that the choice of the type of flux plays a crucial role in protecting the metal from oxidation. Getting rid of the residual smelting slag in the bloom during the refining may require the use of more and more flux as the cleaning process progresses.

In terms of operating steps, we also tried to understand the distribution of forging inclusions in the primary cleaning steps, where the porosity of the metal is the highest and the potential trapping of fluxes is the greatest (see section 4.4). We were able to show that, in samples 1_1_3 and 1_2_3, inclusions from glass fluxes do not appear to have been generated in any significant proportion during this initial stage of work.

Thus, contrary to what had been expected, refining has turned out to be the less propitious work sequence for generating forging inclusions by using fluxes. Firstly, the porosities of the bloom do not seem to trap significant amounts of flux during this phase. Second, the use of flux itself in this phase seems questionable because of its lack of effectiveness.

\begin{tabular}{|c|c|c|c|c|c|}
\hline & & & & & \\
\hline & \multicolumn{2}{|c|}{ Bloom 1 (glass) } & Bloom 2 (glass) & \multicolumn{2}{|c|}{ Bloom 3 (none) } \\
\hline Initial mass in $\mathrm{g}$ & \multicolumn{2}{|c|}{2222} & 1817 & \multicolumn{2}{|c|}{4284} \\
\hline After Step 1 in g (bloom refining) & \multicolumn{2}{|c|}{1018} & 917 & \multicolumn{2}{|c|}{1887} \\
\hline \multirow[t]{2}{*}{ Loss } & \multicolumn{2}{|r|}{$54 \%$} & $50 \%$ & \multicolumn{2}{|r|}{$56 \%$} \\
\hline & $\begin{array}{l}\text { Mass 1- } \\
1 \text { (glass) }\end{array}$ & $\begin{array}{l}\text { Mass 1-2 } \\
\text { (CM slag) }\end{array}$ & mass 2 (none) & $\begin{array}{l}\text { mass 3-1 } \\
\text { (none) }\end{array}$ & $\begin{array}{l}\text { mass } 3-2 \\
\text { (glass) }\end{array}$ \\
\hline Mass after $1^{\text {st }}$ sampling in $g$ & 484 & 534 & 841 & 863 & 951 \\
\hline $\begin{array}{l}\text { After Step } 2 \text { in } g \text { ( } 1^{\text {st }} \text { folding and } \\
\text { welding) }\end{array}$ & 385 & 386 & 652 & 639 & 756 \\
\hline Loss & $20 \%$ & $28 \%$ & $22 \%$ & $26 \%$ & $21 \%$ \\
\hline Mass after $2^{\text {nd }}$ sampling in $\mathrm{g}$ & 341 & 345 & 608 & 609 & 683 \\
\hline $\begin{array}{l}\text { After Step } 3 \text { in g ( } 2^{\text {nd }} \text { folding and } \\
\text { welding) }\end{array}$ & 286 & 262 & 460 & 447 & 560 \\
\hline Loss & $16 \%$ & $24 \%$ & $24 \%$ & $27 \%$ & $18 \%$ \\
\hline
\end{tabular}

Table 3: Mass of original blooms, intermediary and final metal pieces, with corresponding loss rates 


\section{Conclusion}

This article is a continuation of research aimed at understanding the chemical filiation of non-metallic inclusions in objects. Since the beginning of the development of these issues, the role of flux in forge have been put forward as a limitation, or at least, a possible constraint to provenance studies based on these inclusions. It aims to provide new insights about the importance of this pollution during forging, on its recognition and on its behaviour.

This contribution took profit of recent developments of analytical setups (SEM-FEG and Silicon-drift detectors) to improve the understanding of the generation and alteration of inclusions in the metal throughout the smithing process. It relies on a versatile workflow to deal with the increasing size of datasets that are generated by the chemical characterization of ancient ferrous alloys. This process produces dense point clouds whose conformation is confronted to structural features of the metal to greatly improve the interpretation of the distinct chemical inclusion groups. An experimental approach, using materials with known chemical characteristics, was used to validate the data processing method. This method can therefore be used routinely on archaeological materials for an efficient identification of slag inclusions, an essential step of provenance studies.

This study also provides further information about the efficiency of the use of fluxes throughout the refining and smithing sequences. It suggests that fluxes are of poor help for refining, and that fusible and lightly ferrous materials such as glass may be more efficient than other materials, such as the Castel-Minier smelting slag. These results will be consolidated by other archaeological experiments, focusing on the chemical filiation between the fluxes used, the formation of new inclusions and the composition of the forging slag, particularly that of the sandy-clayey slag. Compared to the archaeological data from workshop sites, this would provide a better understanding of the techniques of anti-oxidants adding and the technical and cultural choices made by blacksmiths.

\section{Aknowledgements}

The authors want to thank Thierry Tonnelier and Marion Pillone, the skilled blacksmiths who have ensured the smooth running of the experiments. The experimental session has been conducted within the frame of the Programme Collectif de Recherche "Paléométallurgie et expérimentations Recherches sur les chaines de production des métaux aux périodes anciennes" (leader: Florian Téreygeol) conducted at the experimental platform at Melle (France). They also want to thank all the people who participated in this experimental session and in particular Marc Leroy, Paul Merluzzo, Enrique Véga and Jean-Charles Méaudre.

\section{References}

Aitchison, J., 1986. The statistical analysis of compositional data. Chapman\&Hall, London.

Baxter, M.J., Freestone, I.C., 2006. Log-Ratio Compositional Data Analysis In Archaeometry. Archaeometry 48, 511-531. https://doi.org/10.1111/j.1475-4754.2006.00270.x

Blakelock, E., Martinon-Torres, M., Veldhuijzen, H., Young, T., 2009. Slag inclusions in iron objects and the quest for provenance: an experiment and a case study. J. Archaeol. Sci. 36, 17451757. 
Charlton, M., 2015. The last frontier in "sourcing": The hopes, constraints and future for iron provenance research. J. Archaeol. Sci. 56, 210-220. https://doi.org/doi:10.1016/j.jas.2015.02.017

Charlton, M., Blakelock, E., Martinón-Torres, M., Young, T., 2012. Investigating the production provenance of iron artifacts with multivariate methods. J. Archaeol. Sci. 39, 2280-2293.

Charlton, M., Crew, P., Rehren, T., Shennan, S., 2010. Explaining the evolution of ironmaking recipes An example from northwest Wales. J. Anthropol. Archaeol. 29, 352-367.

Crew, P., 2000. The influence of clay and charcoal ash on bloomery slags, in: Tizzoni, C.C., Tizzoni, M. (Eds.), II Ferro Nelle Alpi, Atti Del Convegno/Iron in the Alps. Proceedings of the Conference. pp. 38-48.

Crew, P., 1991. The experimental production of prehistoric bar iron. J. Hist. Metall. Soc. 25, 21-36.

Crew, P., Crew, S., 1994. The experimental production of bar iron, in: Mangin, M. (Ed.), . Presented at the La sidérurgie ancienne de l'Est de la France dans son contexte européen. Archéologie et archéométrie, Les Belles Lettres, pp. 175-176.

Dillmann, P., Fluzin, P., Urteaga, M., 1997. Refining of an experimental biscaïan bloom from Agorregi, in: Crew, P., Crew, S. (Eds.), . Presented at the Early ironworking in Europe, Archaeology and experiment, International conference, CSA-UISPP, Snowdonia national park, pp. 73-75.

Dillmann, P., L'Héritier, M., 2007. Slag inclusion analyses for studying ferrous alloys employed in French medieval buildings: supply of materials and diffusion of smelting processes. J. Archaeol. Sci. 34, 1810-1823.

Disser, A., Dillmann, P., Leroy, M., L'Héritier, M., Bauvais, S., Fluzin, P., 2016. Iron supply for the building of Metz cathedral: new methodological development for provenance studies and historical considerations. Archaeometry 58.

Fluzin, P., 2002. Apport de l'archéométrie à la restitution de la chaîne opératoire en sidérurgie ;matériaux et procédés. Etudes métallographiques, in: 6 Ème Cours d'archéologie d'Andorre ;l'obtention Du Fer Par Le Procédé Direct Du IV Ėme Au XIX Ème Siècle. Govern D'Andorra, Ministeri de Cultura, Andorra la Vella, p. 388.

Hartigan, J.A., Hartigan, P.M., 1985. The Dip Test of Unimodality. Ann. Stat. 13, 70-84. https://doi.org/10.1214/aos/1176346577

Hedges, R.E.M., Salter, C., 1979. Source determination of iron currency bars through the analysis of slag inclusions. Archaeometry 21, 161-175.

Helsel, D., 2010. Much Ado About Next to Nothing: Incorporating Nondetects in Science. Ann. Occup. Hyg. 54, 257-262. https://doi.org/10.1093/annhyg/mep092

Leblanc, J.-C., 2002. Sur l'identification de la chaîne opératoire de forgeage du fer antique, associée à l'archéométrie des battitures (Thèse de doctorat). Université Toulouse 3 Paul Sabatier, 1969...., France.

Leroy, M., Mangin, M., Laurent, H., Boukezzoula, M., Raissouni, B., 2000. La sidérurgie dans l'est de la Gaule. L'organisation spatiale de la production de l'âge du Fer et haut Moyen Age, in: Mines et Métallurgies En Gaule : Recherches Récentes, Gallia. CNRS Editions, Paris, pp. 157-162.

Leroy, M., Merluzzo, P., Le Carlier, C., 2015. Archéologie du fer en Lorraine. Minette et production du fer en bas fourneaux dans l'Antiquité et au Moyen-Age.

Leroy, M., Ploquin, A., 1994. Approche archéométrique de la proto-industrie du fer: les conditions de réduction des minerais de fer de Lorraine et la chaîne opératoire dans la sidérurgie antérieur à l'apparition du haut fourneau. Rev. Archéom. 18, 53-64.

Leroy, S., Cohen, S.X., Verna, C., Gratuze, B., Téreygeol, F., Fluzin, P., Bertrand, L., Dillmann, P., 2012. The medieval iron market in Ariège (France). Multidisciplinary analytical approach and multivariate analyses. J. Archaeol. Sci. 39, 1080-1093.

Little, R.J.A., Rubin, D.B., 2019. Statistical Analysis with Missing Data, 3 edition. ed. WileyInterscience, Hoboken, N.J.

Mahé-Le-Carlier, C., Ploquin, A., 1999. Typologie et caractèrisation des scories de réduction de la métallurgie du fer. Rev. Archéom. 23, 59-69. 
Paynter, S., Crew, P., Blakelock, E., Hatton, G., 2015. Spinel-rich slag and slag inclusions from a bloomery smelting and smithing experiment with a sideritic ore (Paynter, Crew, et. al. 2015). Hist. Metall. 49, 126-143.

Serneels, V., Ploquin, A., Fluzin, Ph., 2001. Archéométrie des déchets de production sidérurgique. Moyens et méthodes d'identification des différents éléments de la chaîne opératoire directe. Gallia 101-121.

Todd, J.A., Charles, J.A., 1978. Ethiopian bloomery iron and the significance of inclusion analysis in iron studies. Hist. Metall. 12, 63-87. 